\title{
Erratum to: Influence of Physical Manipulations on Short-Term Salt Marsh Morphodynamics: Examples from the North and Mid-Atlantic Coast, USA
}

\author{
Tracy Elsey-Quirk ${ }^{1,3} \cdot$ Susan C. Adamowicz ${ }^{2}$
}

Published online: 13 August 2015

(C) Coastal and Estuarine Research Federation 2015

\section{Erratum to: Estuaries and Coasts}

DOI 10.1007/s12237-015-0013-9

In the original article there was an error in the legends of Figs. 3 and 4. "Levee and Pool" should be replaced by "Berm and Pool." Following are the corrected figures:

The online version of the original article can be found at http://dx.doi.org/ 10.1007/s12237-015-0013-9.

Tracy Elsey-Quirk tquirk@1su.edu

Department of Biodiversity, Earth and Environmental Science, Drexel University, 1900 Benjamin Franklin Parkway, Philadelphia, PA 19103, USA

2 United States Fish and Wildlife Service, Rachel Carson National Wildlife Refuge, 321 Port Rd., Wells, ME 04090, USA

3 Present address: Department of Oceanography and Coastal Sciences, Louisiana State University, 3173 Energy, Coast and Environment Building, Baton Rouge, LA 70803, USA
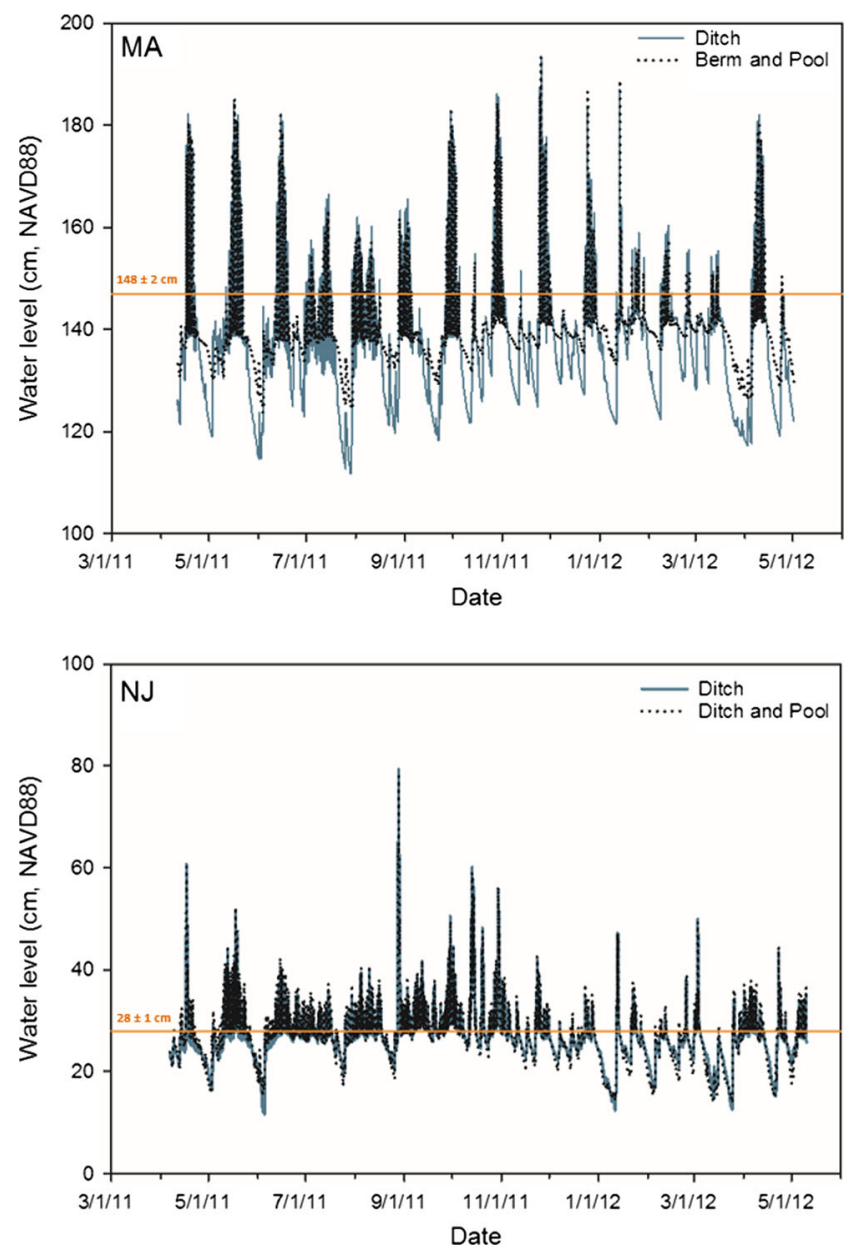

Fig. 3 Water level relative to NAVD88 in salt marshes with different management histories in Plum Island Sound, MA, and Barnegat Bay, NJ, from April 2011 to May 2012. Marsh surface elevations (represented by horizontal line) were similar among treatment areas at probe locations 

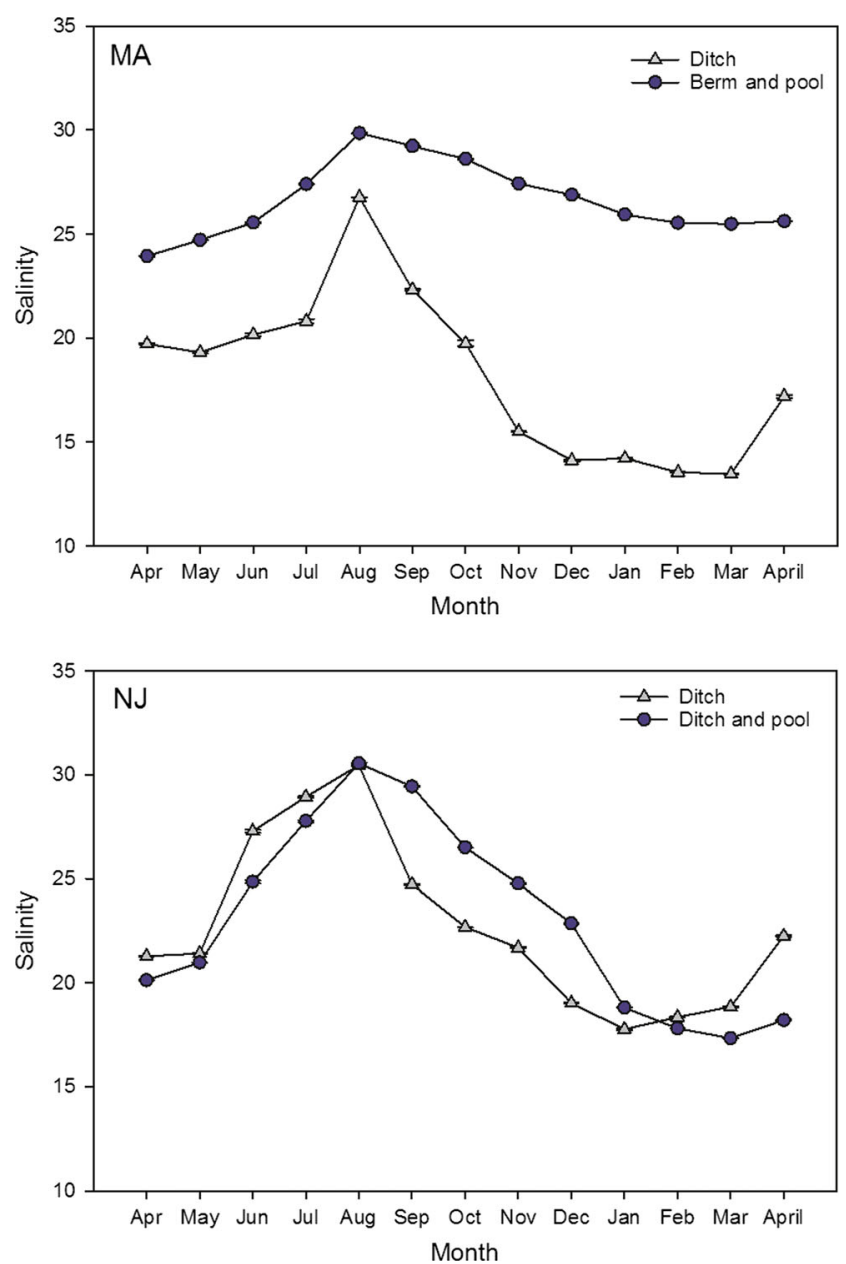

Fig. 4 Average monthly salinity approximately $80 \mathrm{~cm}$ below the surface of salt marshes differing in management history in Plum Island Sound, MA and Barnegat Bay, NJ from April 2011 to May 2012 ( \pm standard error) 